\title{
Chapter 10 \\ Removal of Blood Amyloid As a Therapeutic Strategy for Alzheimer's Disease: The Influence of Smoking and Nicotine
}

\author{
Nobuya Kitaguchi, Kazunori Kawaguchi, and Kazuyoshi Sakai
}

\begin{abstract}
Accumulation of amyloid $\beta$ protein $(A \beta)$ in the brain causes cognitive impairment in Alzheimer's disease (AD). The nature of the relationship between smoking and $\mathrm{AD}$ or dementia has been controversial. However, a recent metaanalysis revealed that smoking is a risk factor for $\mathrm{AD}$. With regard to nicotinic acetylcholinergic receptors (nAChRs), both AD and control patients that smoke have been reported to show an increase in ${ }^{3} \mathrm{H}$-cytisine (an $\alpha 4 \beta 4 \mathrm{nAChR}$ agonist) binding in the temporal cortex. The $\alpha 7 \mathrm{nAChR}$ is also a key factor in AD pathology, particularly in relation to internalization of $A \beta s$. Furthermore, there are many reports showing the neuroprotective effects of nicotine. The internalization of $A \beta$ may lead to $A \beta$ clearance in the brain.

We hypothesized that an extracorporeal system that rapidly removes $\mathrm{A} \beta$ from the blood may accelerate $A \beta$ clearance from the brain. We have reported that (1) several medical materials including hemodialyzers can effectively remove blood $A \beta$, (2) the concentrations of blood $\mathrm{A} \beta \mathrm{s}$ decreased during hemodialysis, (3) removal of blood $\mathrm{A} \beta$ enhanced $\mathrm{A} \beta$ influx into the blood (ideally from the brain), resulting in maintenance or improvement of cognitive function, and (4) A $\beta$ deposition in the brain of hemodialysis patients was significantly lower than in controls. Smoking affected blood $\mathrm{A} \beta$ removal efficiencies and brain atrophy. We believe this Extracorporeal Blood A $\beta$ Removal Systems (E-BARS) may contribute as a therapy for AD.
\end{abstract}

Keywords Alzheimer's disease $\cdot$ Amyloid $\beta \cdot \mathrm{A} \beta \cdot$ Blood purification $\cdot$ Hemodialysis $\cdot$ Dialyzer $\cdot$ HDC $\cdot$ E-BARS

\footnotetext{
N. Kitaguchi $(\bowtie) \cdot$ K. Kawaguchi $\cdot$ K. Sakai

Faculty of Clinical Engineering, School of Health Science, Fujita Health University,

Toyoake, Japan

e-mail: nkitaguc@fujita-hu.ac.jp
} 


\subsection{Introduction: Amyloid $\beta$ Protein in Alzheimer's Disease}

One of the major pathological changes associated with Alzheimer's disease (AD) is the deposition of amyloid $\beta$ protein $(\mathrm{A} \beta)$ as senile plaques and an increase in $\mathrm{A} \beta$ peptides in the brain (Kuo et al. 1996; Selkoe 2001). There are several A $\beta$ species in the brain and plasma that are approximately $4 \mathrm{kDa}$ in weight such as the 40 -amino acid $A \beta_{1-40}$ and the 42-amino acid $A \beta_{1-42}$. A $\beta_{1-42}$ aggregates more easily and is more toxic (Hung et al. 2008), forming soluble $A \beta$ oligomers that can cause synapse loss and affect long-term potentiation in hippocampal neurons (Walsh et al. 2002). One mechanism proposed to underlie the increase in brain $\mathrm{A} \beta$ is reduced $\mathrm{A} \beta$ clearance rather than enhanced $\mathrm{A} \beta$ production, particularly in sporadic $\mathrm{AD}$ cases. $\mathrm{A} \beta$ production in the brains of AD patients was reported to be similar to that of normal subjects, yet $\mathrm{A} \beta$ clearance from $\mathrm{AD}$ brains was approximately $30 \%$ lower than in controls (Mawuenyega et al. 2010). In other words, it may be possible to treat AD by increasing $A \beta$ clearance from the brain.

Recently, an anti-Ab monoclonal antibody that selectively targets aggregated forms of $\mathrm{A} \beta$, aducanumab, was reported to be effective in improving cognitive function and reducing the brain $\mathrm{A} \beta$ burden, as measured by brain $\mathrm{A} \beta$ imaging (Sevigny et al. 2016). Similarly to anti-A $\beta$ antibodies (Hock et al. 2003; Sevigny et al. 2016), peripheral administration of albumin, another $A \beta$-binding substance, was effective in improving cognitive function in $\mathrm{AD}$ patients in a Phase 2 study, and is currently undergoing a Phase 3 trial in AD patients (Boada et al. 2009, 2016).

We hypothesized that the rapid removal of $A \beta$ from the blood by an extracorporeal system (E-BARS; extracorporeal blood $A \beta$ removal system) may act as a peripheral $A \beta$ sink from the brain, as shown in Fig. 10.1 (Kawaguchi et al. 2010). Smoking could affect the blood flow in the brain resulting in a change in the excretion of $\mathrm{A} \beta$ from the brain into the blood.

\subsection{Smoking, Nicotine, and AD}

Determining the exact nature of the relationship between smoking and AD or dementia has been controversial. However, a recent meta-analysis revealed that smoking is a risk factor for $\mathrm{AD}$, as described below. These controversial findings may be due to the mixed effects of smoke itself and components of tobacco such as nicotine. 


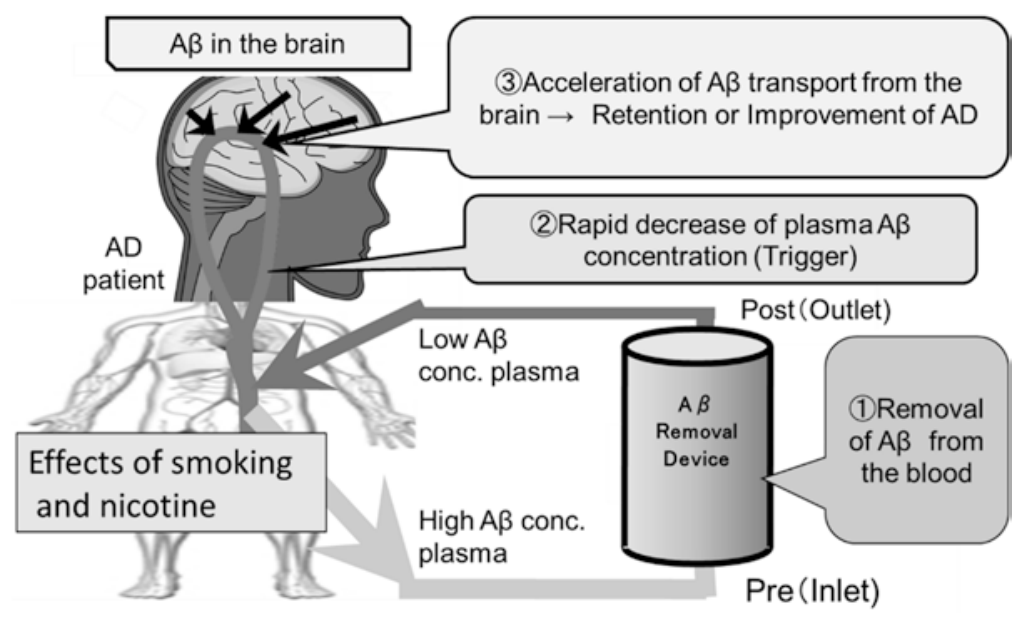

Fig. 10.1 Schema of the extracorporeal blood A $\beta$ removal system (E-BARS) for the treatment of Alzheimer's disease (AD). Our hypothesis: the rapid reduction of $A \beta$ concentrations in the blood by apheresis technology may act as a trigger for enhancing the excretion of $A \beta$ from the brain, resulting in cognitive improvement. (Taken from Kawaguchi et al. 2010 and modified)

\subsubsection{Smoking and AD Prevalence}

Sabia et al. (2008) reported that ex-smokers had a $30 \%$ lower risk of poor vocabulary and low verbal fluency. However, the correlation between smoking history and cognitive decline was inconsistent in longitudinal analysis. Despite this ameliorative effect of smoking on memory (Sabia et al. 2008), the risk of AD was reported to be unaffected by any measure of tobacco consumption (Garcia et al. 2010). Contrary to these favorable or neutral effects of smoking on dementia, there are many reports showing that smoking has a deleterious influence on AD risk. Lower $\mathrm{AD}$ risk was observed in alcohol drinkers of both genders who had never smoked $(\mathrm{OR}=0.37,95 \% \mathrm{CI}: 0.21,0.65)$, regardless of the presence of apolipoprotein E4 (APOع4). Ott et al. (1998) showed that smokers had an increased risk of dementia (relative risk 2.2 [95\% CI: 1.3-3.6]) and AD (relative risk 2.3 [95\% CI: 1.3-4.1]) compared with never smokers, based on a study of 6870 people aged 55 years and older. Smoking was a strong risk factor for AD in individuals without the APOع4 allele (relative risk 4.6 [95\% CI: 1.5-14.2]), but had no effect in participants with this allele (relative risk 0.6 [95\% CI: 0.1-4.8]). By meta-analysis of 19 prospective studies with at least 12 months of follow-up, Anstey et al. (2007) concluded that elderly smokers had increased risks of dementia and cognitive decline. Current smokers at baseline, relative to never smokers, had risks of 1.79 (95\% CI: 1.43, $2.23)$ for $\mathrm{AD}$ and 1.78 (95\% CI: 1.28, 2.47) for vascular dementia. Compared to those who had never smoked, current smokers at baseline also showed greater 
yearly declines in Mini-Mental State Examination scores over the follow-up period. Compared to former smokers, current smokers at baseline showed an increased risk of AD and an increased decline in cognitive ability (Anstey et al. 2007). Furthermore, Barnes and Yaffe (2011) reported that smoking was associated with a higher risk of $\mathrm{AD}$ (relative risk 1.59 [95\% CI: 1.15, 2.20]), and that a $10 \%$ reduction in smoking prevalence could potentially lower AD prevalence by about 412,000 cases worldwide and by almost 51,000 cases in the USA, while a $25 \%$ reduction in smoking prevalence could potentially prevent more than 1 million AD cases worldwide and 130,000 cases in the USA.

\subsubsection{AD Pathology and Smoking}

Recently, an interesting animal study on AD pathology was reported that used cigarette smoke rather than administration of some components of tobacco such as nicotine. When APP/PS1 transgenic mice were exposed to smoke from cigarettes, AD pathology, such as $\mathrm{A} \beta$ deposition and the Iba1-labeled area indicating an inflammatory response, was enhanced in the cortex and hippocampus. This enhancement was observed in the high-dose smoking group but not in the low-dose group (MorenoGonzalez et al. 2013).

Contrary to the animal study, it has been reported that smoking reduces both soluble and insoluble $A \beta_{1-40}$ and $A \beta_{1-42}$ in the frontal cortex and $A \beta_{1-40}$ in the temporal cortex and hippocampus in AD patients (Hellström-Lindahl et al. 2004).

\subsubsection{Nicotinic Acetylcholinergic Receptors and Aßs}

Regarding nicotinic acetylcholinergic receptors (nAChRs), both AD and control patients that smoked showed increased ${ }^{3} \mathrm{H}$-cytisine (an agonist of the $\alpha 4 \beta 4 \mathrm{nAChR}$ ) binding in the temporal cortex (Hellström-Lindahl et al. 2004). Further, A $\beta$ levels in the brain was reduced in this study. Therefore, these authors proposed that a selective $\mathrm{nAChR}$ agonist could be a novel protective therapy for AD.

The $\alpha 7 \mathrm{nAChR}$ is also a key factor in AD pathology, particularly in relation to internalization of $A \beta$ s. Soluble $A \beta$ is known to bind to the $\alpha 7 \mathrm{nAChR}$ with high affinity (Wang et al. 2000). By in vitro experimentation with SH-SY5Y cells, Yang et al. (2014) revealed that extracellular $A \beta_{1-42}$ was internalized by the cells and accumulated in endosomes/lysosomes and mitochondria. This internalization was mediated through an $\alpha 7 \mathrm{nAChR}$-dependent pathway related to the activation of p38 MAPK and ERK1/2. The authors proposed that blockade of the $\alpha 7 \mathrm{nAChR}$ may have a beneficial effect by limiting intracellular accumulation of amyloid in the AD brain, thereby representing a potential therapeutic target for AD. 
However, there are many articles showing the neuroprotective effects of nicotine. The internalization of $A \beta$ may lead to $A \beta$ clearance from the brain. Akaike and Shimohama's research group first demonstrated the neuroprotective effect of nicotine on $\mathrm{A} \beta$ toxicity (Kihara et al. 1997). Concomitant administration of nicotine with $\mathrm{A} \beta_{25-35}$ ameliorated the death of rat cortical neurons induced by $\mathrm{A} \beta$ toxicity. In addition, the selective $\alpha 7 \mathrm{nAChR}$ antagonist, $\alpha$-bungarotoxin, blocked this neuroprotective effect of nicotine. This group also revealed that stimulation of the $\alpha 7$ $\mathrm{nAChR}$ protected neurons against $\mathrm{A} \beta$-enhanced glutamate neurotoxicity via PI3K (Kihara et al. 2001). Shimohama's research group reported that treatment of rat microglia with galantamine, an acetylcholinesterase inhibitor, significantly enhanced microglial $A \beta$ phagocytosis via the $\mathrm{nAChR}$ pathway (Takata et al. 2010). This group also revealed early accumulation of CD68-positive microglia at $\mathrm{A} \beta$ deposition sites and gradual reduction of $A \beta$ in an $A \beta$-injected AD mouse model, which indicates the importance of the $\alpha 7 \mathrm{nAChR}$ in microglia as a therapeutic target in AD (Matsumura et al. 2015).

\subsection{Our Hypothesis of a Therapeutic System for AD by Removal of Blood A $\beta$}

As described earlier, one mechanism proposed to underlie increased brain $\mathrm{A} \beta$ in $\mathrm{AD}$ is reduced $A \beta$ clearance rather than an increase in $A \beta$ production, particularly in sporadic $\mathrm{AD}$ cases. Therefore, it may be possible to treat $\mathrm{AD}$ by enhancing $\mathrm{A} \beta$ clearance from the brain. There are several known $A \beta$ transporters such as those involved in the A $\beta$ influx pathway from the brain into the blood; e.g., LRP1 or APOE (Donahue et al. 2006; Bell et al. 2007), and RAGE (Silverberg et al. 2010), which is also known to mediate an $A \beta$ influx pathway into the brain. In addition, perivascular elimination of $A \beta$ in brain capillaries has been proposed (e.g., Morris et al. 2014).

$\mathrm{A} \beta$ concentrations in the cerebrospinal fluid (CSF) of AD patients are almost 100 times higher than those in plasma. A $\beta$ concentrations in the CSF in cases of AD are reported to be 7.4-42.7 ng/ml for $A \beta_{1-40}$ and $0.12-0.67 \mathrm{ng} / \mathrm{ml}$ for $A \beta_{1-42}$ (Schoonenboom et al. 2005). Concentrations in the plasma of AD patients are reported to be $190.1 \pm 61.7 \mathrm{pg} / \mathrm{ml}$ for $\mathrm{A} \beta_{1-40}$ and $23.0 \pm 15.5 \mathrm{pg} / \mathrm{ml}$ for $\mathrm{A} \beta_{1-42}$ (Lopez et al. 2008). In brief, there are large gradients with respect to $A \beta$ concentrations between the brain and plasma. Therefore, removing A $\beta$ from the blood could accelerate $A \beta$ transfer from the brain, thereby reducing the $A \beta$ burden in the brain.

Peripheral administration of $A \beta$-binding substances, such as anti-A $\beta$ antibodies, non-immunogenic substances, and albumin, can reduce the $A \beta$ burden in the brain. However, attempts to use $A \beta$-binding substances in the blood in a therapeutic context resulted in the formation of $A \beta$ complexes with the binding substances inside the body, which were sometimes retained in the plasma for a long period of time (DeMattos et al. 2001). A $\beta$ antibodies generated by passive immunization or by active immunization using synthetic $A \beta$ peptides reduced the occurrence of senile 
plaques and somewhat improved cognitive impairment in AD patients (Schenk et al. 1999; Hock et al. 2003). Furthermore, non-immunogenic A $\beta$-binding substances, such as GM1 ganglioside or gelsolin, also decreased the $\mathrm{A} \beta$ burden in the brain when they were peripherally injected into mouse models of AD (Matsuoka et al. 2003). Currently, a clinical trial is in progress where AD patients are being treated using intravenous administration of albumin, an A $\beta$-binding substance (Boada et al. 2009). In this Phase 2 trial, plasma exchange (discard) removes the plasma of $A D$ patients, which contains $A \beta$-albumin complexes, and a new albumin solution is introduced into the blood as a replacement solution; the results thus far suggest that this therapy has improved cognitive function in AD subjects. The Phase 3 trial is now also underway (Boada et al. 2016).

Based on these observations, the removal of $A \beta$ from the blood could act as peripheral drainage and an $A \beta$ sink from the brain. We proposed that the E-BARS, which transfers $\mathrm{A} \beta$ out of the body, may be useful as a therapy for AD (Kawaguchi et al. 2010) (Fig. 10.1). The rapid reduction of $A \beta$ concentrations in the blood could act as a trigger to enhance $A \beta$ excretion from the brain, resulting in cognitive improvement.

\subsection{Definition of A $\beta$ Removal Activities of the Devices}

The A $\beta$ removal activities assessed in our study were: (1) the removal rate for batch analysis in vitro, (2-1) the removal efficiency based on the concentration change at pre-/post-application of the $A \beta$ removal device, (2-2) the reduction rate of $A \beta$ in the whole blood circulation, and (2-3) the filtration rate. The definitions were as follows:

1. Batch analysis in vitro:

Adsorptive materials were mixed with $A \beta$ solutions or plasma and shaken for the designated time.

Removal Rate $(\%)=100 \times\left(1-\frac{A \beta \text { concentration with materials at the designated time }}{A \beta \text { concentration without adsorbents at the same time }}\right)$

2. Flow analysis in vitro and the hemodialysis session

2-1 The $A \beta$ removal efficiency of a dialyzer was defined as follows:

Removalefficiency $(\%)=$

$100 \times$

$\left\{1-\frac{\text { concentration of } A \beta \text { after leaving the dialyzer(device) at a designated time }}{\text { concentration of } A \beta \text { before entering the dialyzer(device }) \text { at that time }}\right\}$ 
2-2 The A $\beta$ reduction rate for the experimental pool solution or the whole blood circulation was defined as follows:

Reduction rate $(\%)=$

$100 \times\left\{1-\frac{A \beta \text { concentration in the pool solution or whole blood circulation at a designated time }}{\text { Initial } A \beta \text { concentration in the pool solution or whole blood circulation }}\right\}$

2-3 The $\mathrm{A} \beta$ filtration rate of a dialyzer was defined as follows:

Filtration $\operatorname{rate}(\%)=$

$100 \times\left\{\frac{\text { concentration of filtrated } A \beta \text { solution at the designated time }}{\text { concentration of } A \beta \text { before the dialyzer at the same time }}\right\}$

\subsection{Adsorption Devices for Blood A $\beta$ Removal}

To obtain suitable materials for the removal of blood $\mathrm{A} \beta$, we firstly investigated adsorptive materials for therapeutic blood purification (apheresis). We employed six materials: hexadecyl-alkylated cellulose particles (HDC), used to remove $\beta_{2^{-}}$ microglobulin in carpal tunnel syndrome; cellulose particles ligated with dextran sulfate (CLD); charcoal (CHA), which is commonly used therapeutically, for example, in hepatic failure; tryptophan-ligated polyvinyl alcohol gel (TRV), used in Guillain-Barré syndrome; and cellulose acetate particles and non-woven polyethylene terephthalate filter, used in ulcerative colitis. Among these materials, HDC and CHA demonstrated a removal rate of almost $99 \%$ for both $A \beta_{1-40}$ and $A \beta_{1-42}$ in batch analysis using synthetic $A \beta$ peptides (Fig. 10.2) (Kawaguchi et al. 2010).

HDC is used in cases where there are complications associated with hemodialysis and, therefore, we were able to investigate $\mathrm{A} \beta$ concentrations before (pre, inlet of) and after (post, outlet of) HDC column in hemodialysis sessions. The high removal efficiency of HDC was maintained at approximately $50 \%$ for both $\mathrm{A} \beta_{1-40}$ and $A \beta_{1-42}$ during a 4-h hemodialysis session, as shown in Table 10.1.

\subsection{Blood A $\beta$ Removal by Hemodialyzers in Hemodialysis}

We previously reported that hemodialyzers showed high A $\beta$ removal activity based on analyses of hemodialysis patients (Kitaguchi et al. 2011, 2015; Kato et al. 2012). Measurements of $\mathrm{A} \beta$ concentrations at pre (inlet of) and post (outlet of) dialyzers during hemodialysis sessions revealed that the hemodialyzers effectively removed both $A \beta_{1-40}$ and $A \beta_{1-42}$ from the plasma of non-diabetic patients. Figure 10.3 shows the $A \beta$ concentrations at the inlet of the dialyzers (Pre) and the outlet of the dialyzers (Post) for each dialysis session $(n=57)$. The average removal efficiencies for 

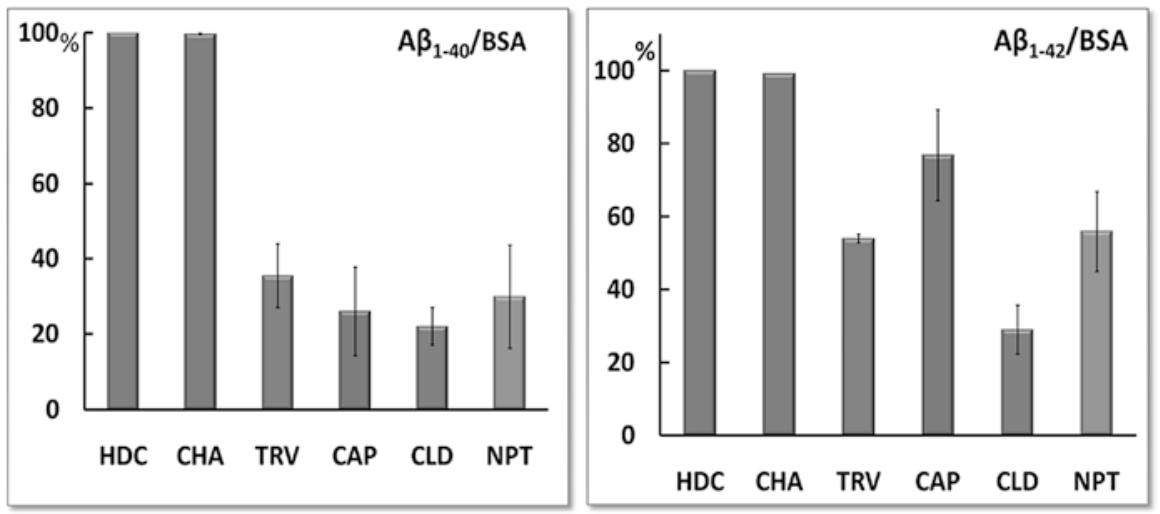

Fig. 10.2 A $\beta$ removal rate in batch analysis with various adsorptives in a batch reaction for $16 \mathrm{~h}$. $H D C$ hexadecyl-alkylated cellulose particles, CHA charcoal, TRV tryptophan-ligated polyvinyl alcohol gel, $C A P$ cellulose acetate particles, $C L D$ cellulose particles ligated with dextran sulfate, $N P T$ non-woven polyethylene terephthalate filter. HDC and CHA showed significantly higher rates than TRV $(\mathrm{p}<0.05)$ for $\mathrm{A} \beta_{1-40}$ removal and a higher tendency than CAP $(\mathrm{p}<0.1)$ for $\mathrm{A} \beta_{1-42}$ removal. (Taken from Kawaguchi et al. 2010)

Table 10.1 Removal efficiencies of HDC columns in hemodialysis

\begin{tabular}{l|l|l}
\hline $\begin{array}{l}\text { Time points during a } \\
\text { hemodialysis session }\end{array}$ & $\mathrm{A} \beta_{1-40}$ & $\mathrm{~A} \beta_{1-42}$ \\
\hline $1 \mathrm{~h}(\mathrm{n}=5)$ & $51.1 \pm 6.6 \%$ & $44.9 \pm 5.0 \%$ \\
\hline $4 \mathrm{~h}(\mathrm{n}=4)$ & $46.1 \pm 6.6 \%$ & $38.2 \pm 5.8 \%$ \\
\hline
\end{tabular}

Taken from Kawaguchi et al. (2010)

$\mathrm{A} \beta_{1-40}$ were $66.0 \%$ at the 1-h point and $52.0 \%$ at the 4-h point of the hemodialysis sessions. Those for $\mathrm{A} \beta_{1-42}$ were $61.1 \%$ and $49.2 \%$, as shown in Fig. 10.3. The removal efficiency in for $A \beta_{1-40}$ was significantly higher than for $A \beta_{1-42}$ both at $1 \mathrm{~h}$ and at $4 \mathrm{~h}$ of each dialysis session ( $<0.0001$ for both time points). Each dialyzer maintained its removal efficiency during the entire dialysis session. This indicates that the dialyzers had sufficient capacity for $A \beta$ removal during the 4-h treatment.

\subsection{Removal of Blood A $\beta$ s Evoked Influx of A $\beta$ s into the Blood}

Due to the effective removal activity of the dialyzers during the hemodialysis sessions (Fig. 10.3), the concentrations of blood A $\beta$ s after 4-h hemodialysis would have been approximately $10 \%$ of the concentrations at the starting point if there had been no A $\beta$ influx into the blood ("Calcd" in Fig. 10.4). However, observed 

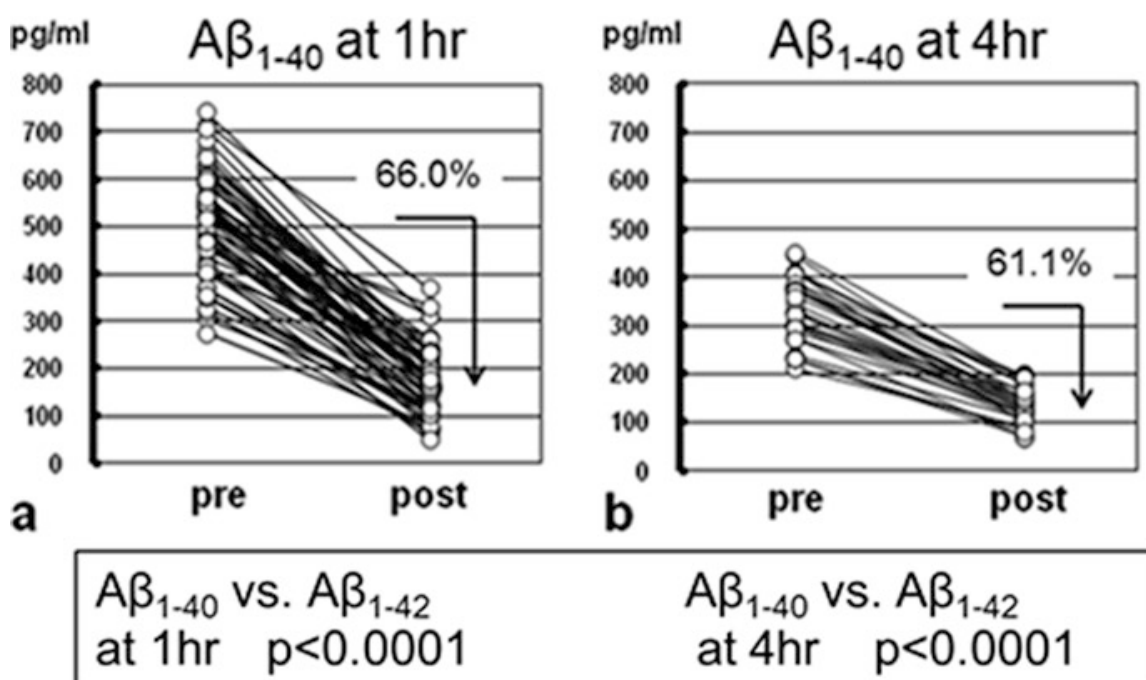

$A \beta_{1-40}$ vs. $A \beta_{1-42}$ at $4 \mathrm{hr} \quad \mathrm{p}<0.0001$

\section{$\mathrm{pg} / \mathrm{ml} \quad A \beta_{1-42}$ at $1 \mathrm{hr}$}

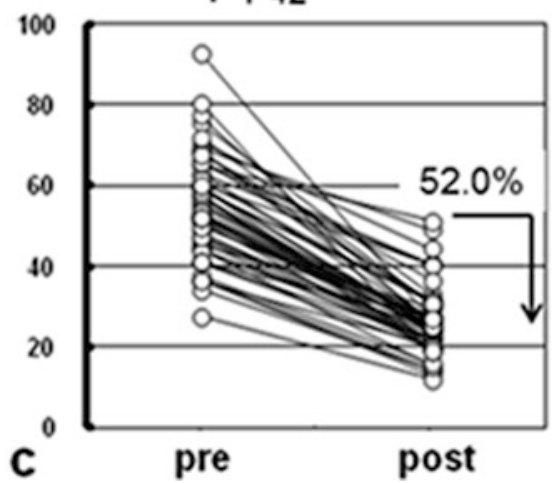

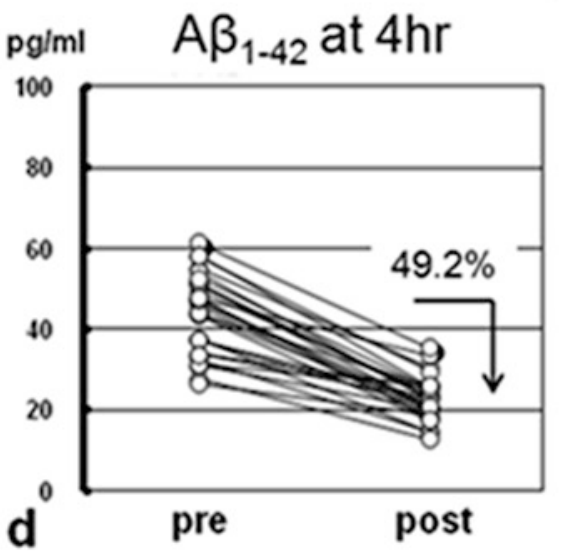

Fig. 10.3 A $\beta$ concentrations measured at pre-/post-dialyzers at 1 and $4 \mathrm{~h}$ in the hemodialysis sessions. $A \beta$ removal efficiencies for both $A \beta_{1-40}$ and $A \beta_{1-42}$ were quite high, with both being approximately $50 \%$ or greater. (a, b) $\mathrm{A} \beta_{1-40} ;(\mathbf{c}, \mathbf{d}) \mathrm{A} \beta_{1-42} ;(\mathbf{a}, \mathbf{c})$ at the 1 -h point of the dialysis sessions; (b, d) at the 4-h point of the dialysis sessions. (Taken from Kato et al. 2012 and modified)

concentrations of blood A $\beta$ s ("Obsd" in Fig. 10.4) were not decreased compared to "Calcd." The differences between "Obsd" and "Calcd" were attributed to A $\beta$ influx into the blood. We calculated the influx based on the differential equation described previously (Kitaguchi et al. 2011). The results of this simulation of 37 non-diabetic hemodialysis patients are shown in Fig. 10.4.

Table 10.2 shows more detailed results of the simulation of $A \beta$ influx with 30 non-diabetic hemodialysis patients (Kitaguchi et al. 2015). The average removal efficiencies at the 1-hr point of the hemodialysis sessions were $67.3 \%$ and $51.3 \%$ for $\mathrm{A} \beta_{1-40}$ and $\mathrm{A} \beta_{1-42}$, respectively. $\mathrm{A} \beta$ influxes during 4-hr hemodialysis were calcu- 


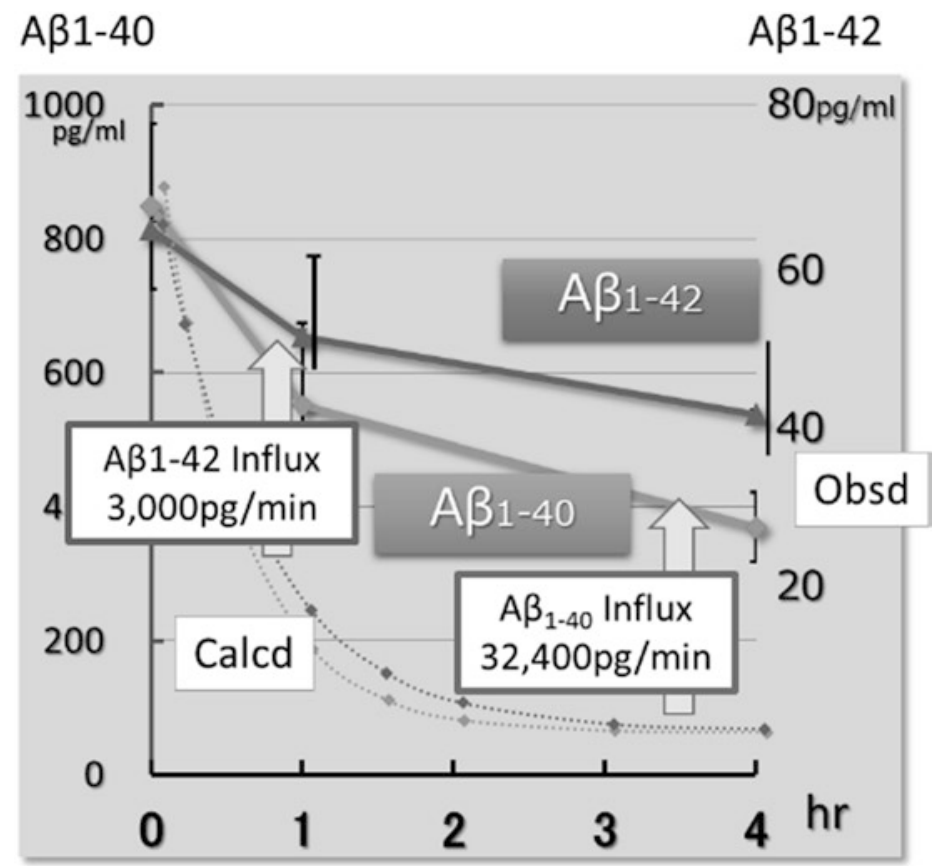

Fig. 10.4 Change in the observed plasma $A \beta$ concentrations in the whole body circulation during hemodialysis sessions (Obsd), and, the calculated plasma $A \beta$ concentrations based on the $A \beta$ removal efficiencies of the dialyzers assuming no $\mathrm{A} \beta$ influx into the blood (Calcd). The arrows indicate $A \beta$ influx during the hemodialysis sessions. (Taken from Kitaguchi et al. 2011 and modified)

lated as $9243 \mathrm{ng}$ and $719 \mathrm{ng}$ for $\mathrm{A} \beta_{1-40}$ and $\mathrm{A} \beta_{1-42}$, respectively, which were around five times the level of pre-existing $A \beta$ s in the blood, that is, $1952 \mathrm{ng}$ and $165 \mathrm{ng}$, just before hemodialysis.

A similar $\mathrm{A} \beta$ influx into the blood was also observed in a rat study using HDC.

\subsection{Are the Influxes of A $\beta$ s into the Blood from the Brain?}

Recently, we reported that $\mathrm{A} \beta$ accumulation in the brains of hemodialysis (HD) patients was significantly lower than that in age-matched non-hemodialysis controls, as assessed by histopathological studies (Sakai et al. 2016). Senile plaques stained with anti-A $\beta$ antibodies were observed more frequently in non-HD subjects and were either sparse or not seen at all in HD patients (Fig. 10.5). Regarding the ratio of senile plaques (plaque-positive/-negative subjects), there were significantly fewer neuritic and cored plaques in HD patients; only 5 of 17 HD patients showed neuritic plaques stained with $4 \mathrm{G} 8$ anti- A $\beta$ antibody, whereas 12 out of 16 non-HD subjects exhibited these plaques. These findings suggest that the brain may be one origin of the $A \beta$ influx during the hemodialysis sessions. 
Table 10.2 Average A $\beta$ influx into the blood during the hemodialysis sessions

\begin{tabular}{|c|c|c|c|c|c|c|c|c|}
\hline \multicolumn{9}{|c|}{$A \beta$ concentrations during hemodialysis sessions $(n=30)$} \\
\hline \multirow[b]{2}{*}{$\begin{array}{l}\text { Time point of HD } \\
\text { session }\end{array}$} & \multicolumn{4}{|c|}{$\mathrm{A} \beta_{1-40}$} & \multicolumn{4}{|c|}{$\mathrm{A} \beta_{1-42}$} \\
\hline & $0 \mathrm{~h}$ & $1 \mathrm{~h}$ & $4 \mathrm{~h}$ & & $0 \mathrm{~h}$ & $1 \mathrm{~h}$ & $4 \mathrm{~h}$ & \\
\hline $\begin{array}{l}\mathrm{A} \beta \text { concentrations } \\
\text { at Pre dialyzer }(\mathrm{pg} / \\
\mathrm{ml})\end{array}$ & 750.7 & 517.7 & 361.8 & & 63.3 & 50.0 & 41.5 & \\
\hline $\begin{array}{l}\text { Removal } \\
\text { Efficiency }(\%) \text { of } \\
\text { Pre/Post dialyzers }\end{array}$ & & 67.3 & & & & 51.3 & & \\
\hline \multirow[t]{2}{*}{$\begin{array}{l}\text { A } \beta \text { removed by } \\
\text { dialyzers (ng) }\end{array}$} & & $(0-1 \mathrm{~h})$ & $(1-4 h)$ & $\begin{array}{l}\text { Total } \\
\text { removed A } \beta \\
(0-4 \text { h) (a) }\end{array}$ & & $(0-1 \mathrm{~h})$ & $(1-4 h)$ & $\begin{array}{l}\text { Total } \\
\text { removed A } \beta \\
(0-4 \text { h) (a) }\end{array}$ \\
\hline & & 3329 & 6925 & 10,254 & & 227 & 549 & 776 \\
\hline \multirow[t]{2}{*}{$\begin{array}{l}\text { Change of } A \beta s \text { in } \\
\text { the blood (ng) }\end{array}$} & 1952 & & 941 & $\begin{array}{l}\text { Decreased } \\
\text { A } \beta(0-4 \text { h) } \\
\text { (b) }\end{array}$ & 165 & & 108 & $\begin{array}{l}\text { Decreased } \\
\text { A } \beta(0-4 \mathrm{~h}) \\
\text { (b) }\end{array}$ \\
\hline & & & & 1011 & & & & 57 \\
\hline $\begin{array}{l}\text { A } \beta \text { influx into the } \\
\text { blood during } \\
\text { hemodialysis } \\
\text { sessions(ng) (a-b) }\end{array}$ & \multicolumn{4}{|l|}{9243} & \multicolumn{4}{|l|}{719} \\
\hline
\end{tabular}

Taken from Kitaguchi et al. (2015)

\subsection{Effects of Hemodialysis, One of the Blood A $\beta$ Removal Methods, on Cognitive Function}

Renal failure is well known to cause cognitive decline. In our cross-sectional study, cognitive function as measured by the MMSE was impaired in renal failure patients who did not receive hemodialysis compared to age-matched healthy controls. However, MMSE scores of hemodialysis patients were similar to those of controls (Fig. 10.6) (Kato et al. 2012).

Figure 10.7 shows the relationship between plasma $A \beta$ concentrations, cognitive function, renal function, and hemodialysis vintage (the duration of hemodialysis) before and after initiation of hemodialysis. Before initiation of hemodialysis, plasma concentrations of both $\mathrm{A} \beta_{1-40}$ and $\mathrm{A} \beta_{1-42}$ increased along with a concomitant decline in renal function. However, when patients were introduced to hemodialysis (after initiation of hemodialysis), an increase in plasma $\mathrm{A} \beta$ concentrations was no longer apparent, but there was instead a slight tendency toward a decrease. Although the cognitive function declined along with the decline in renal function, this was maintained following initiation of hemodialysis (bottom of Fig. 10.7).

In the prospective study with 18 and 36 months follow-up, average MMSE scores did not significantly change, as shown in Fig. 10.8a, b. However, analysis of the change in individual subjects revealed that most hemodialysis patients maintained 
a) $4 G 8\left(\right.$ anti $\left.A \beta_{17-24}\right)$ stained senile plaques
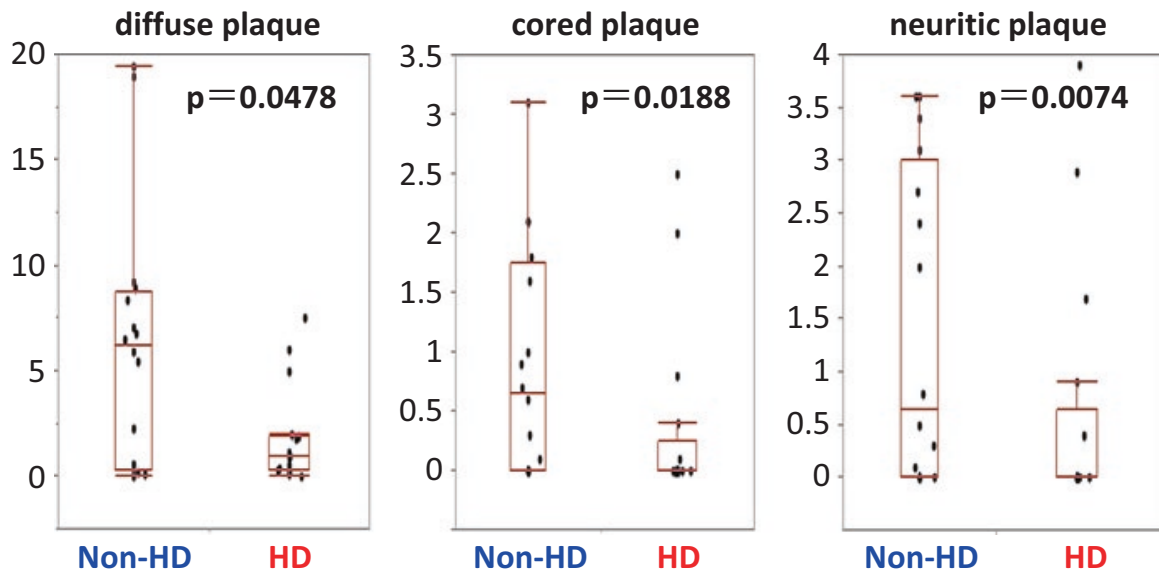

b) $\quad$ E2 (anti $A \beta_{1-16}$ ) stained senile plaques
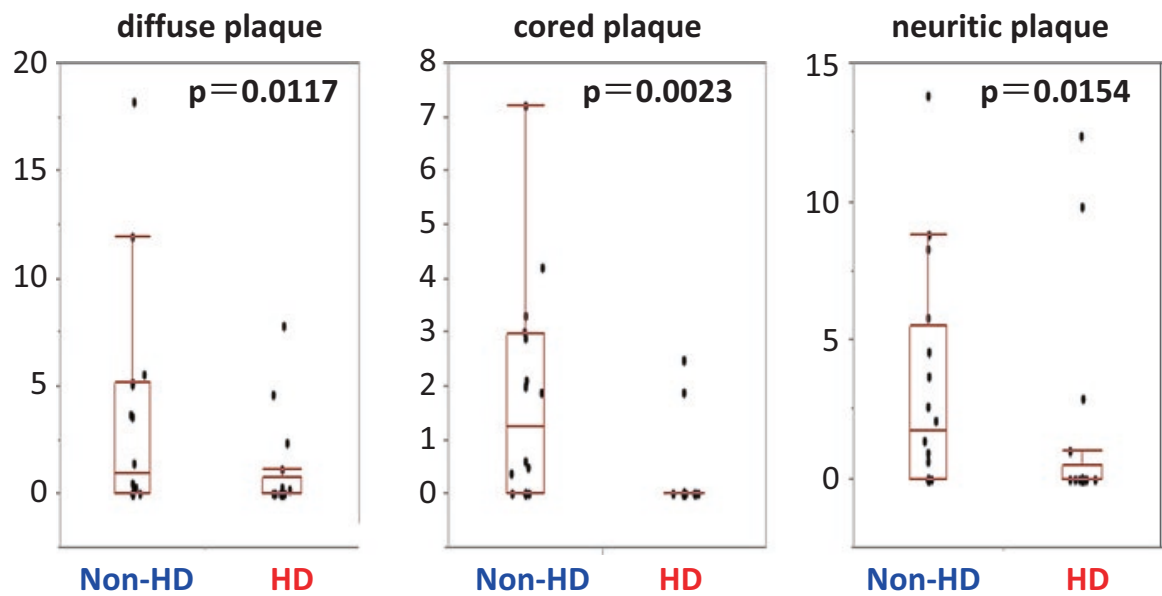

Fig. 10.5 Comparison of senile plaques in patients who had undergone hemodialysis (HD) with those who had not undergone HD (non-HD). (a) Stained with the anti-A $\beta_{17-24}$ antibody 4G8; (b) stained with the anti-A $\beta_{1-16}$ antibody DE2. The numbers of all types of $A \beta$ deposition (diffuse, cored, and neuritic plaques) were significantly lower in HD patients. HD, $\mathrm{n}=17$; non-HD, $\mathrm{n}=16$. (Taken from Sakai et al. 2016 and modified) 


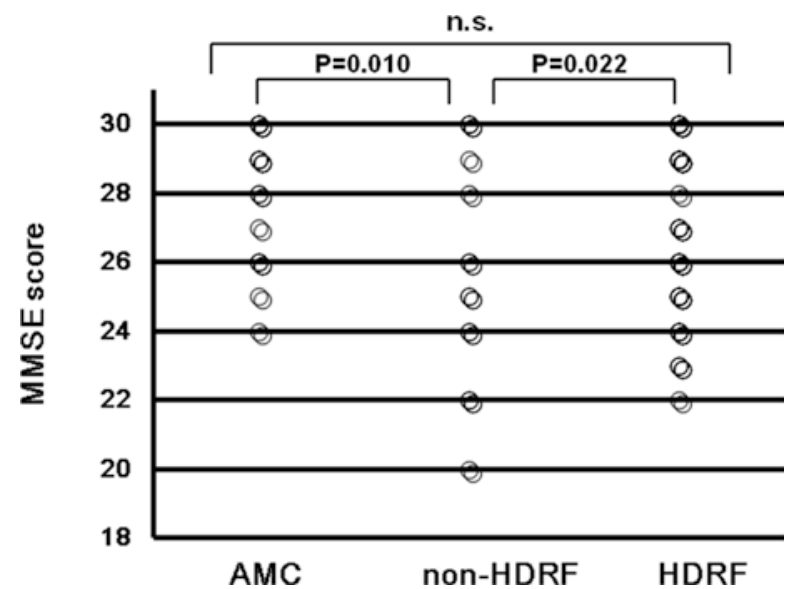

Fig. 10.6 Cognitive function deteriorated in renal failure; however, hemodialysis appeared to promote recovery or maintenance of this. AMC, age-matched healthy controls $(n=17)(66.6 \pm$ 4.1 years old, 5 male, 12 female); non-HDRF, renal failure patients without hemodialysis $(n=26)$ (66.6 \pm 14.7 years old, 18 male, 8 female); HDRF, renal failure patients who received hemodialysis three times a week $(\mathrm{n}=57)(69.4 \pm 3.8$ years old, 29 male, 28 female $)$. MMSE Mini-Mental State Examination. (Taken from Kato et al. 2012)

or improved their cognitive function, with the exception of patients that showed white matter ischemia at baseline (Fig. 10.8c). This suggests that hemodialysis, with $A \beta$ removal from the blood three times a week, may have a positive effect on cognitive function but has almost no influence on the cognitive effects of brain ischemia.

Furthermore, using a database of over 200,000 hemodialysis patients in Japan, the risk of dementia was revealed to be significantly lower in the patient subgroup with a longer duration of hemodialysis in subjects without diabetes (Nakai et al. 2018).

\subsection{Effects of Smoking on Removal of Blood A $\beta$}

We then investigated the effects of smoking on $A \beta$ removal efficiencies in hemodialysis. Subjects were non-diabetic hemodialysis patients; $\mathrm{n}=57,29$ male and 28 female; age, $69.4 \pm 3.8$ years old (59-76 years old); duration of hemodialysis, $13.9 \pm 9.4$ years $(1-37$ years); 28 smokers and 29 non-smokers, with "smoker" defined as a patient who had ever smoked (former smokers and current smokers). Information regarding the duration of smoking, the number of cigarettes per day, and the brands of cigarettes were obtained by interview with each patient. The product of the duration and the number of cigarettes per day was also used for analysis.

Interestingly, removal efficiencies for both $A \beta_{1-40}$ and $A \beta_{1-42}$ in smokers significantly decreased during the 4 -h hemodialysis sessions (Table 10.3). The efficiencies 


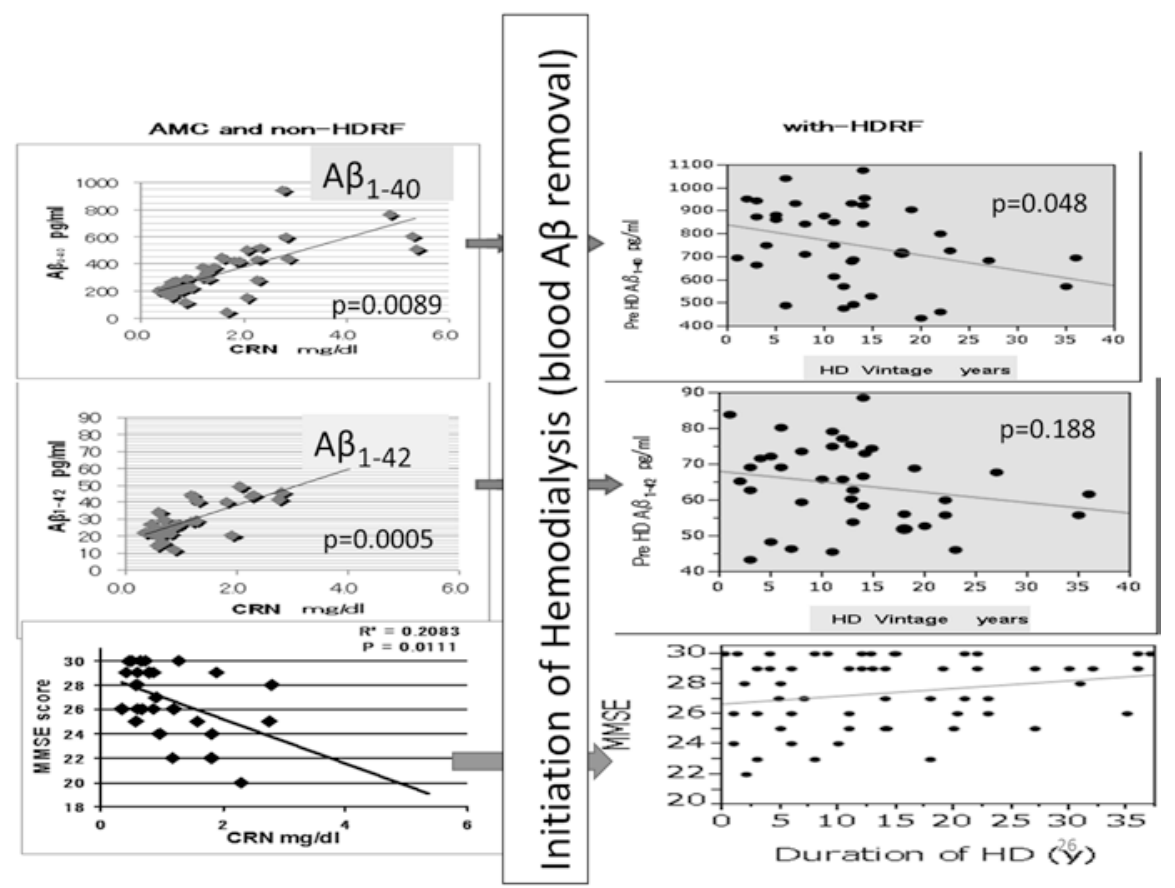

Fig. 10.7 Summary of cross-sectional study of renal failure patients before/after initiation of hemodialysis (HD). The central box indicates initiation of hemodialysis. Left of the central box, data from renal failure patients without hemodialysis (non-HDRF) are shown. Right of the central box, data from hemodialysis patients (with-HDRF) are shown. Vertical axis: upper, plasma $A \beta_{1-40}$ concentrations; middle, plasma $\mathrm{A} \beta_{1-42}$ concentrations; lower, the Mini-Mental State Examination (MMSE) score (30 indicates no mistakes). Plasma for measuring A $\beta$ concentrations after the initiation of hemodialysis was sampled at the beginning of each hemodialysis session. Horizontal axis: before initiation of hemodialysis, plasma creatinine concentrations (CRN), which indicate decline of renal function; after initiation of hemodialysis, the vintage (duration) of hemodialysis. (Data from Kato et al. 2012)

for non-smokers showed a tendency to increase, which was insignificant, rather than a decrease. The reason for this difference is unclear at present. One possibility is that $A \beta$ species in the blood of smokers may have certain characteristics that cause saturation of $A \beta$ adsorption or clogging of the inner surface of dialyzer membranes. A second possibility is that $\mathrm{A} \beta$ species flowing into the blood during hemodialysis may be more difficult to remove using a dialyzer in smokers than in non-smokers.

However, there is a limitation regarding this speculation on the effects of smoking. The ratio of male/female subjects was higher in smokers than in non-smokers. Therefore, the differences between smokers and non-smokers could be partially attributable to gender. 


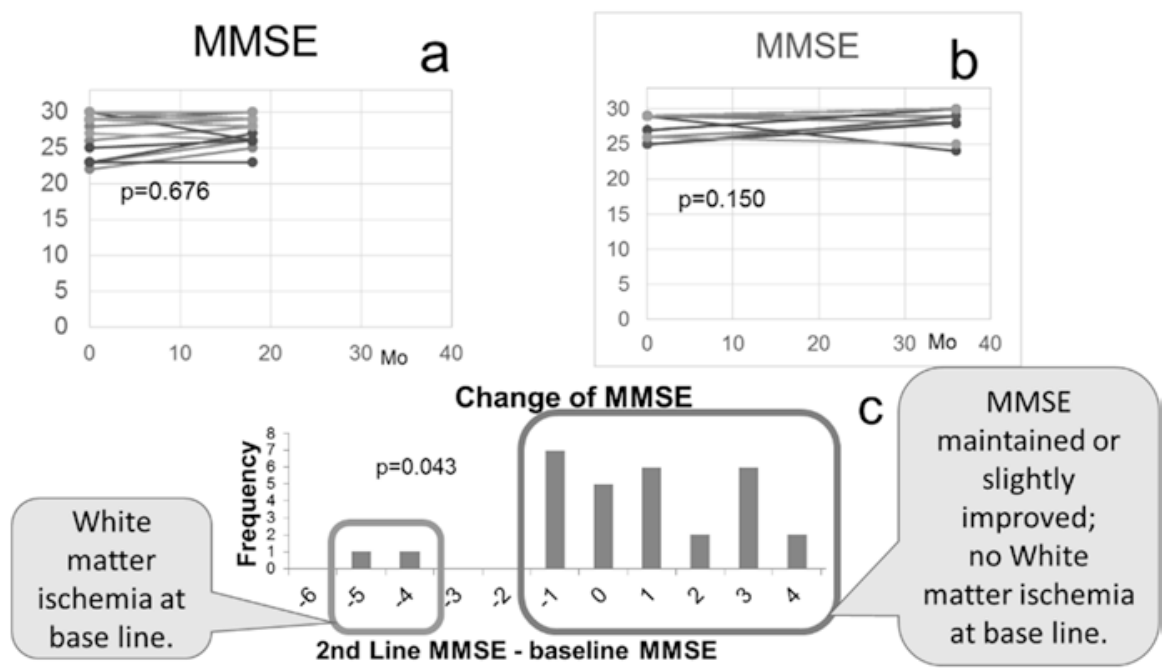

Fig. 10.8 Change in cognitive function of hemodialysis patients in prospective studies. (a) MiniMental State Examination (MMSE) changes over 18 months; (b) MMSE changes over 36 months; (c) change in MMSE from baseline for each patient. A change of -1 to 4 is regarded as maintained or improved. Patients whose MMSE declined by -4 and -5 showed white matter ischemia at baseline. (Taken from Kitaguchi et al. 2015 and modified)

Table 10.3 Effects of smoking; comparison of $\mathrm{A} \beta$ removal efficiencies at pre-/post dialyzers in hemodialysis sessions

\begin{tabular}{|c|c|c|c|}
\hline Removal efficiencies \% & & $1 \mathrm{~h}$ & $4 \mathrm{~h}$ \\
\hline \multirow[t]{2}{*}{$\mathrm{A} \beta_{1-40}$} & Smoker & $\begin{array}{l}70.0 \pm 9.6 \\
\qquad p=0.0016\end{array}$ & $60.0 \pm 8.6$ \\
\hline & Non-smoker & $65.4 \pm 9.9$ & $70.4 \pm 20.3$ \\
\hline \multirow[t]{2}{*}{$\mathrm{A} \beta_{1-42}$} & Smoker & $\begin{array}{l}56.8 \pm 9.1 \\
L_{p}=0.049\end{array}$ & $53.7 \pm 6.2$ \\
\hline & Non-smoker & $50.2 \pm 11.4$ & $55.3 \pm 8.5$ \\
\hline
\end{tabular}

\subsection{Effects of Smoking on Cognitive Function and Brain Atrophy in Renal Failure Patients}

Figure 10.9 indicates that there appears to be no clear difference between the smoker and non-smoker cognitive function, as measured by the MMSE, in our study with a small sample size. The MMSE scores of smokers were similar to those of nonsmokers in all three groups; age-matched healthy controls (AMC, seven smokers, ten non-smokers), renal failure patients who did not need hemodialysis (non-HDRF, 


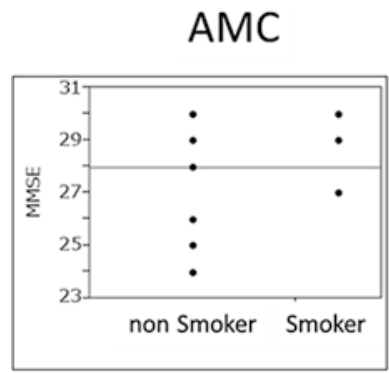

non-HDRF

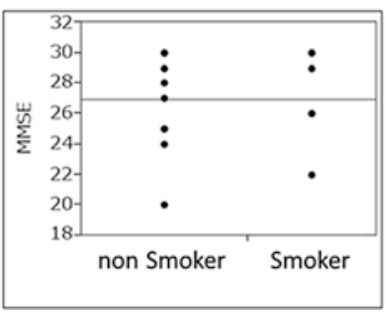

HDRF

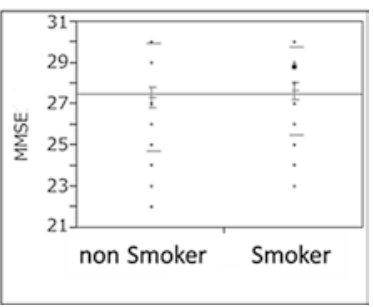

Fig. 10.9 The cognitive function of smokers and non-smokers was similar in our study. The patients were the same as those represented in Fig. 10.6 except that smoking history was obtained from only 16 non-HDRF patients. $A M C$ age-matched healthy controls (seven smokers, ten nonsmokers), non-HDRF renal failure patients without hemodialysis (seven smokers, nine nonsmokers), $H D R F$ severe renal failure patients who received hemodialysis three times a week (28 smokers, 29 non-smokers). MMSE Mini-Mental State Examination

Frontal/Temporal Lobe

a

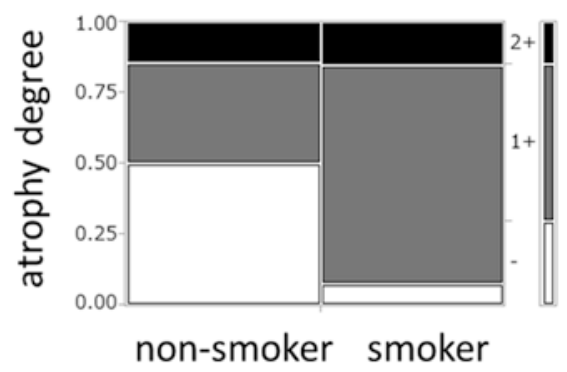

Temporal/Parietal Lobe

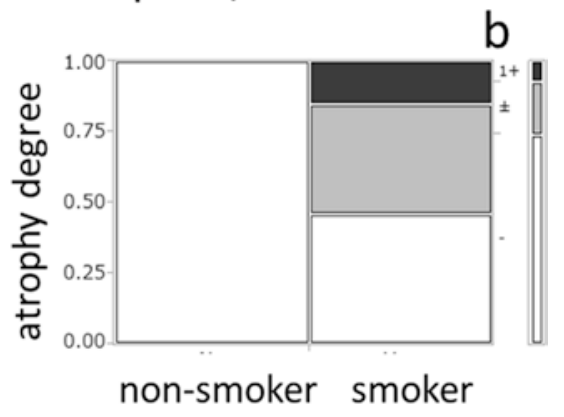

Fig. 10.10 Brain atrophy in smokers and non-smokers. Frontal/temporal atrophy and temporal/ parietal atrophy was more severe in smokers than in non-smokers, as detected by brain CT scans $\left(\mathrm{p}=0.0465\right.$ and $\mathrm{p}=0.0062$, respectively, by the $\chi^{2}$ test). (Taken from Kitaguchi et al. 2015)

seven smokers, seven non-smokers), and severe renal failure patients who received hemodialysis three times a week (HDRF, 28 smokers, 29 non-smokers).

However, brain CT scans revealed that there were differences in brain atrophy between smokers and non-smokers. Frontal/temporal and temporal/parietal atrophies were more severe in smokers than in non-smokers, as shown in Fig. 10.10 ( $\mathrm{p}=0.0465$ and $\mathrm{p}=0.0062$, respectively, by the $\chi^{2}$ test). This suggests that the effects of smoking on the brain may not be sufficiently serious to affect cognitive function in our study, or that hemodialysis including $A \beta$ removal from the blood three times a week may maintain cognitive function despite the presence of more severe atrophies in smokers. 


\subsection{Closing}

As described above, removal of blood $\mathrm{A} \beta$ may enhance $\mathrm{A} \beta$ influx into the blood from the brain, resulting in maintenance or improvement of cognitive function. We believe that the E-BARS could contribute as a therapy for Alzheimer's disease. With respect to smoking, the patient's history in this regard may have some effect on brain atrophy and on the forms of $\mathrm{A} \beta$ s existing in the blood. Additional study will be necessary in the future to further clarify this.

\section{References}

Anstey KJ, von Sanden C, Salim A, O'Kearney R (2007) Smoking as a risk factor for dementia and cognitive decline: a meta-analysis of prospective studies. Am J Epidemiol 166:367-378

Barnes DE, Yaffe K (2011) The projected effect of risk factor reduction on Alzheimer's disease prevalence. Lancet Neurol 10:819-828

Bell RD, Sagare AP, Friedman AE, Bedi GS, Holtzman DM, Deane R, Zlokovic BV (2007) Transport pathways for clearance of human Alzheimer's amyloid beta-peptide and apolipoproteins $\mathrm{E}$ and $\mathrm{J}$ in the mouse central nervous system. J Cereb Blood Flow Metab 27:909-918

Boada M, Ortiz P, Anaya F, Hernández I, Muñoz J, Núñez L, Olazarán J, Roca I, Cuberas G, Tárraga L, Buendia M, Pla RP, Ferrer I, Páez A (2009) Amyloid-targeted therapeutics in Alzheimer's disease: use of human albumin in plasma exchange as a novel approach for Abeta mobilization. Drug News Perspect 22:325-239

Boada M, Ramos-Fernández E, Guivernau B, Muñoz FJ, Costa M, Ortiz AM, Jorquera JI, Núñez L, Torres M, Páez A (2016) Treatment of Alzheimer disease using combination therapy with plasma exchange and haemapheresis with albumin and intravenous immunoglobulin: rationale and treatment approach of the AMBAR (Alzheimer Management By Albumin Replacement) study. Neurologia 31:473-481

DeMattos RB, Bales KR, Cummins DJ, Dodart JC, Paul SM, Holtzman DM (2001) Peripheral anti-A beta antibody alters CNS and plasma A beta clearance and decreases brain A beta burden in a mouse model of Alzheimer's disease. Proc Natl Acad Sci U S A 98:8850-8855

Donahue JE, Flaherty SL, Johanson CE, Duncan JA 3rd, Silverberg GD, Miller MC, Tavares R, Yang W, Wu Q, Sabo E, Hovanesian V, Stopa EG (2006) RAGE, LRP-1, and amyloid-beta protein in Alzheimer's disease. Acta Neuropathol 4:405-415

García AM, Ramón-Bou N, Porta M (2010) The effects of tobacco exposure before the age of onset of $\mathrm{AD}$ was investigated as a case-control study. Isolated and joint effects of tobacco and alcohol consumption on risk of Alzheimer's disease. J Alzheimers Dis 20:577-586

Hellström-Lindahl E, Mousavi M, Ravid R, Nordberg A (2004) Reduced levels of Abeta 40 and Abeta 42 in brains of smoking controls and Alzheimer's patients. Neurobiol Dis 15:351-360

Hock C, Konietzko U, Streffer JR, Tracy J, Signorell A, Müller-Tillmanns B, Lemke U, Henke K, Moritz E, Garcia E, Wollmer MA, Umbricht D, de Quervain DJ, Hofmann M, Maddalena A, Papassotiropoulos A, Nitsch RM (2003) Antibodies against beta-amyloid slow cognitive decline in Alzheimer's disease. Neuron 38:547-554

Hung LW, Ciccotosto GD, Giannakis E, Tew DJ, Perez K, Masters CL, Cappai R, Wade JD, Barnham KJ (2008) Amyloid-b peptide (Ab) neurotoxicity is modulated by the rate of peptide aggregation: Ab dimers and trimers correlate with neurotoxicity. J Neurosci 28:11950-11958

Kato M, Kawaguchi K, Nakai S, Murakami K, Hori H, Ohashi A, Hiki Y, Ito S, Shimano Y, Suzuki N, Sugiyama S, Ogawa H, Kusimoto H, Mutoh T, Yuzawa Y, Kitaguchi N (2012) Potential 
therapeutic system for Alzheimer's disease: removal of blood Abs by hemodialyzers and its effect on the cognitive functions of renal-failure patients. J Neural Transm 119:1533-1544

Kawaguchi K, Kitaguchi N, Nakai S, Murakami K, Asakura K, Mutoh T, Fujita Y, Sugiyama S (2010) Novel therapeutic approach for Alzheimer's disease by removing amyloid- $\beta$ protein from the brain with an extracorporeal removal system. J Artif Organs 13:31-37

Kawaguchi K, Saigusa A, Yamada S, Gotoh T, Nakai S, Hiki Y, Hasegawa M, Yuzawa Y, Kitaguchi $\mathrm{N}$ (2016) Toward the treatment for Alzheimer's disease: adsorption is primary mechanism of removing amyloid $\beta$ protein with hollow-fiber dialyzers of the suitable materials, Polysulfone and polymethyl methacrylate. J Artif Organs 19:149-158

Kihara T, Shimohama S, Sawada H, Kimura J, Kume T, Kochiyama H, Maeda T, Akaike A (1997) Nicotinic receptor stimulation protects neurons against beta-amyloid toxicity. Ann Neurol 42:159-163

Kihara T, Shimohama S, Sawada H, Honda K, Nakamizo T, Shibasaki H, Kume T, Akaike A (2001) Alpha 7 nicotinic receptor transduces signals to phosphatidylinositol 3-kinase to block A beta-amyloid-induced neurotoxicity. J Biol Chem 276:13541-13546

Kitaguchi N, Kawaguchi K, Nakai S, Murakami K, Ito S, Hoshino H, Hori H, Ohashi A, Shimano Y, Suzuki N, Yuzawa Y, Mutoh T, Sugiyama S (2011) Reduction of Alzheimer's disease amyloid- $\beta$ in plasma by hemodialysis and its relation to cognitive functions. Blood Purif 32:57-62

Kitaguchi N, Hasegawa M, Ito S, Kawaguchi K, Hiki Y, Nakai S, Suzuki N, Shimano Y, Ishida O, Kushimoto H, Kato M, Koide S, Kanayama K, Kato T, Ito K, Takahashi H, Mutoh T, Sugiyama S, Yuzawa Y (2015) A prospective study on blood $A \beta$ levels and the cognitive function of patients with hemodialysis: a potential therapeutic strategy for Alzheimer's disease. J Neural Transm 122:1593-1607

Kuo YM, Emmerling MR, Vigo-Pelfrey C, Kasunic TC, Kirkpatrick JB, Murdoch GH, Ball MJ, Roher AE (1996) Water-soluble Abeta (N-40, N-42) oligomers in normal and Alzheimer disease brains. J Biol Chem 271:4077-4081

Lopez OL, Kuller LH, Mehta PD, Becker JT, Gach HM, Sweet RA, Chang YF, Tracy R, DeKosky ST (2008) Plasma amyloid levels and the risk of AD in normal subjects in the Cardiovascular Health Study. Neurology 70:1664-1671

Matsumura A, Suzuki S, Iwahara N, Hisahara S, Kawamata J, Suzuki H, Yamauchi A, Takata K, Kitamura Y, Shimohama S (2015) Temporal changes of CD68 and $\alpha 7$ nicotinic acetylcholine receptor expression in microglia in Alzheimer's disease-like mouse models. J Alzheimers Dis 44:409-423

Matsuoka Y, Saito M, LaFrancois J, Saito M, Gaynor K, Olm V, Wang L, Casey E, Lu Y, Shiratori C, Lemere C, Duff K (2003) Novel therapeutic approach for the treatment of Alzheimer's disease by peripheral administration of agents with an affinity to $\beta$-Amyloid. J Neurosci 23:29-33

Mawuenyega KG, Sigurdson W, Ovod V, Munsell L, Kasten T, Morris JC, Yarasheski KE, Bateman RJ (2010) Decreased clearance of CNS beta-amyloid in Alzheimer's disease. Science 330:1774

Moreno-Gonzalez I, Estrada LD, Sanchez-Mejias E, Soto C (2013) Smoking exacerbates amyloid pathology in a mouse model of Alzheimer's disease. Nat Commun 4:1495

Morris AWJ, Carare RO, Schreiber S, Hawkes CA (2014) The cerebrovascular basement membrane: role in the clearance of $\beta$-amyloid and cerebral amyloid angiopathy. Front Aging Neurosci 6:1-9

Nakai S, Wakai K, Kanda E, Kawaguchi K, Sakai K, Kitaguchi N (2018) Is hemodialysis itself a risk factor for dementia? An analysis of nationwide registry data of patients on maintenance hemodialysis in Japan. Ren Replace Ther 4:12. https://doi.org/10.1186/s41100-018-0154-y

Ott A, Slooter AJ, Hofman A, van Harskamp F, Witteman JC, Van Broeckhoven C, van Duijn CM, Breteler MM (1998) Smoking and risk of dementia and Alzheimer's disease in a populationbased cohort study: the Rotterdam Study. Lancet 351:1840-1843

Sabia S, Marmot M, Dufouil C, Singh-Manoux A (2008) Smoking history and cognitive function in middle age from the Whitehall II study. Arch Intern Med 168:1165-1173

Sakai K, Senda T, Hata R, Kuroda M, Hasegawa M, Kato M, Abe M, Kawaguchi K, Nakai S, Hiki Y, Yuzawa Y, Kitaguchi N (2016) Patients that have undergone hemodialysis exhibit lower 
amyloid deposition in the brain: evidence supporting a therapeutic strategy for Alzheimer's disease by removal of blood amyloid. J Alzheimers Dis 51:997-1002

Schenk D, Barbour R, Dunn W, Gordon G, Grajeda H, Guido T, Hu K, Huang J, Johnson-Wood K, Khan K, Kholodenko D, Lee M, Liao Z, Lieberburg I, Motter R, Mutter L, Soriano F, Shopp G, Vasquez N, Vandevert C, Walker S, Wogulis M, Yednock T, Games D, Seubert P (1999) Immunization with amyloid-beta attenuates Alzheimer-disease-like pathology in the PDAPP mouse. Nature 400:173-177

Schoonenboom NS, Mulder C, Van Kamp GJ, Mehta SP, Scheltens P, Blankenstein MA, Mehta PD (2005) Amyloid beta 38, 40, and 42 species in cerebrospinal fluid: more of the same? Ann Neurol 58:139-142

Selkoe DJ (2001) Alzheimer's disease: genes, proteins, and therapy. Physiolo Rev 81:741-766

Sevigny J, Chiao P, Bussière T, Weinreb PH, Williams L, Maier M, Dunstan R, Salloway S, Chen T, Ling Y, O’Gorman J, Qian F, Arastu M, Li M, Chollate S, Brennan MS, Quintero-Monzon O, Scannevin RH, Arnold HM, Engber T, Rhodes K, Ferrero J, Hang Y, Mikulskis A, Grimm J, Hock C, Nitsch RM, Sandrock A (2016) The antibody aducanumab reduces A $\beta$ plaques in Alzheimer's disease. Nature 537:50-56

Silverberg GD, Miller MC, Messier AA, Majmudar S, Machan JT, Donahue JE, Stopa EG, Johanson CE (2010) Amyloid deposition and influx transporter expression at the blood-brain barrier increase in normal aging. J Neuropathol Exp Neurol 69:98-108

Takata K, Kitamura Y, Saeki M, Terada M, Kagitani S, Kitamura R, Fujikawa Y, Maelicke A, Tomimoto H, Taniguchi T, Shimohama S (2010) Galantamine-induced amyloid-\{beta\} clearance mediated via stimulation of microglial nicotinic acetylcholine receptors. J Biol Chem 285:40180-40191

Walsh DM, Klyubin I, Fadeeva JV, Cullen WK, Anwyl R, Wolfe MS, Rowan MJ, Selkoe DJ (2002) Naturally secreted oligomers of amyloid b protein potently inhibit hippocampal long-term potentiation in vivo. Nature 416:535-539

Wang HY, Lee DHS, D’Andrea MR, Peterson PA, Shank RP, Reitz AB (2000) Beta-amyloid(1-42) binds to $\alpha 7$ nicotinic acetylcholine receptor with high affinity-implications for Alzheimer's disease pathology. J Biol Chem 275:5626-5632

Yang WN, Ma KG, Chen XL, Shi LL, Bu G, Hu XD, Han H, Liu Y, Qian YH (2014) Mitogenactivated protein kinase signaling pathways are involved in regulating $\alpha 7$ nicotinic acetylcholine receptor-mediated amyloid- $\beta$ uptake in SH-SY5Y cells. Neuroscience 278:276-290

Open Access This chapter is licensed under the terms of the Creative Commons Attribution 4.0 International License (http://creativecommons.org/licenses/by/4.0/), which permits use, sharing, adaptation, distribution and reproduction in any medium or format, as long as you give appropriate credit to the original author(s) and the source, provide a link to the Creative Commons license and indicate if changes were made.

The images or other third party material in this chapter are included in the chapter's Creative Commons license, unless indicated otherwise in a credit line to the material. If material is not included in the chapter's Creative Commons license and your intended use is not permitted by statutory regulation or exceeds the permitted use, you will need to obtain permission directly from the copyright holder.

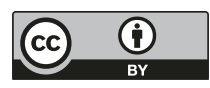

